\section{REPORT OF A CASE}

\section{RECOVERY FROM APPARENT DEATH INDUCED BY THE INHALATION OF CHLOROFORM:}

A CASE DESCRIBED TO SHOW THE THERAPEUTIC VALUE OF INVERSION OF THE BODY WHEN THERE IS SYNCOPE FROM CEREBRAL ANEMIA; AND TO AID IN THE ELUCIDATION OF CHRONIC CHLOROFORM POISONING.*

\section{BY SIR JOHN ROSE CORMACK,}

Chevalier of the Legion of Honour; M.D.Edin. and Paris; F.R.S.E.; Fellow of the Royal Colleges of Physicians of London and Edinburgh;

Physician to the Hertford British Hospital, Paris; etc.

J. A., a lady's maid, aged 27 , was admitted, under my care, to the Hertford British Hospital on January 30 th, IS74. She was very hysterical, weak, and anæmic. She had chronic disease of the hip-joint and necrosis of the femur. On the day of admission, a small piece of dead bone was removed. On February 25 th, deep incisions were made and drainage-tubes introduced. These measures were resorted to in consequence of intense pain in the hip, thigh, and leg, tumefac. tion and tension of the whole right gluteal region, and the supposed existence of deep-seated matter under the gluteal fascia. From its being necessary to place the patient almost on her face, I operated without putting her under the influence of chloroform. 'The operation occasioned great pain, which lasted for some hours, though opiates were freely administered, and large warm poultices applied to the hip and thigh. During the evening, she had two hysterical attacks, characterised by excitement and weeping. From that date, to May $25^{\text {th, the }}$ patient's general state improved very much. The discharge by the tubes was at times profuse, and at times moderate. The internal medication consisted chiefly in the use of the syrup of the lacto-phosphate of iron, and short occasional courses of the compound tincture of cinchona and the compound tincture of valerian. She had a liberal diet, embracing meat and wine.

On May 25th, I resolved to put her under the influence of chloroform, so as to be able to make, without torture to the patient, a thorough exploration, and remove a loose piece of bone which could be felt by the probe. At I0.30 A.M. on that day, all was ready for the operation. The patient was placed on her left side, recumbent, and with the face quite free. The day was hot, but a light breeze was play. ing. The patient lay before, and within three feet of, a large casement window, which could, if a stream of fresh air were required, be thrown wide open in an instant. The necessary instruments and appliances for the operation, and for the possible emergencies of chloroformisation, were ready ; and all arrangements were completed, without alarming or exciting the patient. I spoke some cheerful words to her, to which she pleasantly responded, expressing great thankfulness that she was to be allowed to inhale chloroform. I looked at my watch, and, calculating that ten or fifteen minutes would elapse before she was ready for the knife, I asked Mr. Vines (then our clinical assistant) to begin the administration, and to proceed slowly in our usual way. This he at once did, by placing near the patient's mouth a napkin folded as a hollow cone, and having within it a small quantity of chloroform. There was a free space of some inches between the towel and the lips of the patient. Within about two minutes, during which $I$ had my watch in $\mathrm{my}$ eye and my hand on the pulse, the patient had passed into a calm sleep, without having spoken a word, moved a limb, or twitched a feature. I pinched the skin of the forearm, which caused her to move the arm a little, but did not occasion any other manifestation on her part. The inhalation of chloroform was now nearly suspended; that is to say, the towel was so far removed from the mouth, that the inhaled chloroform vapour must have been so diluted with atmospheric air, as to augment but slightly the existing anæsthesia. I kept my hand on the patient's pulse for two minutes more; she was then profoundly chloroformed, being quite insensible to pinching. The breathing was natural : the pulse, though slow, was quite regular, and of fair strength. At this moment, that is to say, at the end of four minutes from the commencement of the inhalation of chloroform, my colleague Dr. Herbert joined me. Just as he entered, I made a free incision, saying almost simultaneously to Dr. Herbert, "I think she is too much under the influence of chloroform". Glancing at her, and feeling her pulse, he replied : "Yes; but the pulse and breathing are all right." No more chloro-

* Read before the Surgical Section at the Annual Meeting of the British Medical Association in Norwich, August 1874 . form was given. Whilst I proceeded with the operation to its completion, the window was thrown open, and Dr. Herbert tried to bring back the patient to consciousness by flapping her face and chest with a wet towel, and speaking to her. This state of matters continued for about ten minutes; during that period, not the slightest signs of consciousness were shown. I had just completed the operation, when $\mathrm{Dr}$. Herbert announced an alarming irregularity and sinking of the pulse. This occurred about twenty minutes from the time at which the administration of the chloroform was commenced. At this crisis, and throughout the whole duration of the unconsciousness, except once for a few minutes, the lips were red, and the face had neither a ghastly nor a pale aspect. This we all remarked, and spoke of at the time. The pulse became more and more irregular and feeble; death seemed imminent. On the proposal of Dr. Herbert, the body of the patient was inverted; that is to say, the heels were held upright and the head downright. (This is sometimes called Nélaton's method. It has been very well described and explained by Dr. Charles Campbell of Paris, in a pamphlet published in Paris during this year, entitled : Etude sur la Tolírance Anesthísique Obstítricale. At p. 34 of that pamphlet, a case is given in which a woman was saved by complete inversion. This case occurred on Nov. 19, 1861. Dr. Marion Sims was operating for vesicovaginal fistula. MM. Nélaton, Beylard, Johnston, and Alan Herbert, were present.) A very striking improvement in the pulse was immediately perceived. The patient was maintained in the inverted position for about four or five minutes; the pulse had then so much improved, that we hoped danger was past. Accordingly, we replaced the woman in the horizontal position, applying at the same time turpentine stupes to the legs, and injecting into the bowel an ounce of brandy beat up with an egg and a small quantity of beef-tea. This injection was retained. The amelioration brought about by the inversion continued, and seemed even to be increasing for five or ten minutes, when it began to diminish gradually, notwithstanding the diligent use of various resuscitory measures, such as placing mustard poultices on various parts of the body in succession, the application of ammonia to the nostrils, and tickling them with a feather. More than once, Dr. Herbert passed his finger into the back of the throat, with a view to draw forward the glottis, should that have been necessary. Just before the inversion of the patient, I transfixed her tongue with a threaded needle, which enabled us, during the whole of the subsequent treatment, to keep the tongue out of the mouth, and the mouth open. Matters became rapidly worse ; again, death seemed to be imminent. We repeated the inversion; it immediately produced an equally favourable result as on its first trial. Indeed, the second yielded even more conspicuously beneficial results than the first trial; and, for this reason, that the condition of the patient was worse immediately before the second than immediately before the first inversion. Immediately before the second inversion, the irregularity and sinking of the pulse had been succeeded by a great diminution in the frequency and force of the respiration; prior to the first inversion, it was very much less affected.

The second inversion, like the first, was continued for about ten minutes. The patient was then replaced in the horizontal position, and the legs were treated as before with turpentine stupes. A turpentine enema was administered : it was retained. The face was, at short intervals, sprinkled with water refrigerated by ice. This was being done about twelve o'clock, when she opened her hitherto closed eyes and looked at those around her with a stupid bewildered gaze. When asked whether she felt any pain, she answered "Yes", with a feeble but distinct voice. When I asked her, where she felt pain, she looked at me steadily, pointed to her chest, and pronounced the word "Weight.". At this time, she could not be got to answer any other questions; she did not say one word in reply to many questions addressed to her; but when spoken to, stared at the person who spoke. For a little time, she decidedly improved. When irritants were applied, the pulse would rise and temporarily become firm and almost full. At half past twelve, she answered several questions, the substance of her replies being to the effect that she was dying, and was suffering less from pain than from a great weight at the chest. She recognised me and one of the nurses, addressing us by our names. She stared at Dr. Herbert, Mr. Vines, and others present with whom she was well acquainted, when she was asked to name them; and said "I know none of them". This return of comparative well-being and consciousness lasted for a very short time. Dr. Herbert had left me to attend to the out-patients, we both believing that all was now likely to go on well. I immediately recalled him in consequence of a relapse. She suddenly relapsed into unconsciousness, the pulse fluttered and fell, and the breathing became very weak, very slow, and occasionally jerking. At the same time, and for the first time since the terrible scene began, her lips and cheeks became deadly pale; for several minutes she seemed on the very verge of death, and for a minute she seemed to be dead, so long an interval occurred 
between her inspirations. Artificial respiration was employed by means of abdominal compression and movement of the arms. Under this treatment, the pulse (which had become imperceptible) returned; but for at least half-an-hour, whenever the artificial respiration was relinquished, the breathing showed an alarming tendency to fail. At this time, the danger seemed even more urgent than it had yet been; for never yet had the respiratory function been so profoundly compromised. Without much hope of permanent benefit, she was inverted; and again with the happiest results. A little later, vomiting came on, which was very difficult ; but it helped much to bring back consciousness.

At half-past one o'clock, Dr. Herbert and I arranged that I might leave, being required elsewhere; and that I should return at four o'clock, he remaining, if necessary, till my return. I came back at four ; and found Mr. Vines alone in charge, Dr. Herbert having left at halfpast three, in consequence of a great amelioration in the symptoms. After I left, however, for nearly an hour there had been several considerable relapses. The irregularity and sinking of pulse were on one of those occasions so great and sudden as to occasion for a few minutes some dread of a fatal issue. On my return, at four o'clock, I found the patient in a state of drowsy semi-consciousness. She evidently did not know where she was, or who the persons were by whom she was surrounded. Her lips were red, and her pulse and breathing almost normal. Slight partial relapses of irregularity and weakness of pulse recurred whilst I remained at the hospital, from 4 to 6 P.M. During that time, she took some beef-tea, swallowing easily.

At ro P.M., Mr. Vines sent me a good account of the patient, so that I did not return to see her till nine next morning, when Dr. Herbert and I saw her together. She was then heavy and drowsy, though able to answer questions collectedly, though not always correctly; and, according to her usual mode of expression, when asked how she felt, she said that she had no headache, but pain and a sense of great weight in the region of the heart. Her chief complaint was of a distressing pain in the muscles of the shoulders and arms ; the result, no doubt, of the movements we had made in employing artificial respiration. She said nothing of feeling pain in the seat of the operation or neighbouring parts. Putting her hand to her tongue, where I had transfixed it with the needle, she said, "there is something wrong with my tongue". Next day, she was still in a state of semi-consciousness. This state went on gradually diminishing in intensity; but three days and three nights had elapsed before it had entirely passed away. At the end of that period, she had resumed her former ways in respect of food, sleep, and intelligence.

The chronic and cataleptiform character of this case of poisoning by chloroform inhalation constitute two of its most remarkable features. Several cases of a somewhat similar character have been described by British and foreign authors. My case tends to confirm the statement of Berend, Casper, and others, that chloroform inhalation may prove fatal after the lapse of many days. After giving an analysis of cases, Casper says : "It can no longer be doubted that there is such a thing as chronic poisoning by chloroform; that is, that the drug, when it does kill, does not always kill instantaneously, but that hours, days, or even weeks, may elapse during which the person anæsthetised remains continuously under the influence of the poison, to which he at length succumbs. This doctrine is evidently of medico-legal importance."* One of Casper's cases relates to a woman who "was chloroformed on the 14th of December, previous to the amputation of her left leg, on account of a comminuted fracture, and who, up to the hour of her death, on the 23 rd of the same month, had never completely recovered her senses, -losi during the inhalation".

As I stated at the commencement of the narrative which I have laid before you, my patient was a weak, anæmic, and hysterical woman.

In such a patient as J. A., it may be truly said, that other causes besides the inhalation of chloroform might, and often do, induce a cataleptic state. But it is also true that in her case, along with the catalepsy, there was in operation an influence due to the anæsthetic vapour. Minutely and well observed cases of a similar character require to be collected and collated. As yet, comparatively few have been published, from which it may be concluded that comparatively few have occurred. I have fully and faithfully recorded all that was seen and done in the case which occurred on May 25th at the Hertford British Hospital, so that my report may contribute to the elucidation of the subject of chronic chloroform-poisoning at any future time, and by any future truth-seeking inquirer.

One of my principal objects in bringing this case before the British Medical Association, is to set forth facts which show, or seem to show, * Handbook of the Practice of Forensic NIcdicine. By J. L. Casper. Translation
of the New Sydenham Society, by Dr. G. W. Balfour. London: 1862. -See page 296 of vol. ii. the therapeutic value of inverting the body when there is syncope from cerebral anæmia. Dr. Herbert, Mr. Vines, and I, were all, at the time, convinced that the inversion produced a powerful effect in restoring the contractions of the heart. I feel certain that the practice proved decidedly beneficial in our hands; and that it is a practice which ought to be resorted to in similar cases. I am, however, also convinced that all the various restorative measures which we employed contributed to bring about recovery. It is impossible to apportion the share of good which was accomplished by each of the means employed. No one can say how far the inversion of the body was the means of restoring life, seeing that artificial respiration was employed-that most wonderful agency in producing resuscitation of the apparently dead. Numerous cases are recorded in which, by means of keeping the patients warm and in the horizontal position, artificial respiration has saved them. Nevertheless, my case showed that, while artificial respiration was of signal benefit when the body was horizontal, inversion for four or five minutes-at intervals-was an useful addition to ordinary resuscitative measures. In the case so graphically described by Dr. Charles Campbell, the duration of inversion was fifteen minutes-a period, I think, unnecessarily, and perhaps even dangerously, long. We all know the benefit of the horizontal position in cases of ordinary fainting. I am far from recommending that, in cases of chloroform-fainting, the inverted position ought to be preferred to the horizontal. I only recommend it to be used, as in the case I have described, for short periodssay for four or five minutes or less-at intervals-and in conjunction with the persevering use of artificial breathing, and the other common measures of recovery and precaution.

I have received the following interesting and valuable letter from Dr. Benjamin W. Richardson. It is published with his permission.

\section{I2, Hinde Street, August IIth, I874.}

MY DEAR CORMACK, - I have read with deep interest your paper on Chronic Poisoning by Chloroform; and I have also read the case so graphically described in Dr. Campbell's French pamphlet, which you were so kind as to send to me. Both cases call fairly for many observations, but I will now deal mainly with yours.

Your case is very rare, but not altogether unique. In one case where Snow administered chloroform to a young woman in King's College Hospital (see my edition of Snow On Chloroform, p. 105), the patient remained unconscious for three days, but recovered without ill effects. In another case, a medical man administered chloroform to a young woman in domestic service (see the same work, pp. 105.6) for the extraction of a tooth. In a few minutes, she burst out into a fit of laughter, and then subsided into unconsciousness. Various measures, including artificial respiration, were used to restore her, from the impression that she was still under the influence of chloroform. Thirtysix hours after the inhalation, Snow was sent for. He found the patient apparently in a profound state of insensibility, and breathing very feebly. Some valerian was, after a time, administered to this patient, and in a few hours the unconsciousness passed away.

I attended a case myself in which similar symptoms followed upon the inhalation, not of chloroform, but of nitrous oxide gas. The gas was administered to this patient, a woman in the prime of life, in order to allow a tooth to be extracted. As sometimes happens from the gas, there was acute and severe convulsive movement during the narcotism, and the woman recovered imperfectly. She succeeded, nevertheless, in going some four hundred yards to reach the Metropolitan underground line, and got into a railway-carriage. Soon afterwards, while travelling, she fell back into unconsciousness, with faintness, extreme pallor, and active convulsion. At first, it was feared that she would die; but she was taken to her home, where she was put to bed semiconscious. The following day, I was summoned to see her. She was still nearly unconscious, and the most I could get her to do was to put out her tongue. Her eye was not sensible when touched, and her pupils were widely dilated. Her pulse was irregular and weak, and her̉ breathing very feeble. I learned that she had been in this state for twenty-four hours, but that at times she was intensely convulsed. I noticed also a fotor of a most peculiar kind from the breath-a fotor due to some substance having the odour of the organic sulphur compound called sulphur alcohol or mercaptan. She had vomited several times, and had taken no food. These symptoms being looked upon as hysterical, leaning towards catalepsy, she was treated as for hysteria. It was six days before the symptoms abated, and at intervals there were recurrent attacks of convulsion. The symptoms throughout caused much anxiety, and recovery was not perfect for many weeks.

Nature of these Cases. - I agree with you distinctly that these cases are all types of hysteria, in what may be called the cataleptic phase of the hysteric disease. As yet, they have only been known to occur in the female 
subject. I do not think it correct to maintain that the persistent unconsciousness is due to the continued action of the narcotic agent administered to produce anæsthesia. There is no evidence to show that chloroform remains in the body even an hour after its administration has ceased; and in the cases I have related, in which nitrous oxide gas was used, it cannot be presumed for a moment that the gas was held within the organism, and was sustaining the unconsciousness for several days. The view I would myself offer is one which I ventured to submit in my report* to the British Association for the Advancement of Science at the Birmingham meeting in 1865 ; viz., that, during certain hysteric states, there is formed in the animal body itself an organic compound which, like certain of the amyl and sulphur compounds, produces, after the manner of a poison, the cataleptic condition. If this be true, it is easily understood how the administration of a volatile narcotic may give a start to the action of the narcotic product already present in the body, and that the effect may be sustained until the producing agent is eliminated by the excretions.

The particular Mode of Treatment by Inversion of the Body.-The mode of treatment followed out in your case recalls to my mind certain experiments, some of which you saw me perform in 1854, and which are published in the Association Medical. Journal of August i8th, of that year. Those experiments, as you will remember, were conducted in order to ascertain the effect of posture of the body on the action of the heart after anæsthesia and loss of blood. I had observed that, when the butcher is killing a calf, the action of the heart of the animal is systematically maintained by him, though hæmorrhage is still going on, by the process of suspending the animal for a time with its head downwards, afterwards laying it horizontally, and again suspending it until the body is completely emptied of blood. The fact led me to experiment, in order to learn the effect on the heart of different positions of the body. The details of the experiments will be found in the number of the Association Journal above referred to, on pages 734 and 5 ; but the gist of them is, that the animals having been made to sleep, by inhalation of the smoke of the lycoperdon giganteum, until respiration had ceased, artificial respiration was established, the thorax was laid open, and the effect of position on the blood within the heart was carefully observed. It was thus found that, when the body had been suspended with the head upwards, until the auricle and ventricle of the right side had ceased to act from deficiency of blood in them, these parts could at once be refilled by the simple plan of laying down the body horizontally; that the right heart, so refilled, would recommence to contract vigorously; that if at the same time, artificial respiration were sustained, the blood would make the pulmonic circuit, and that the left side would also recommence to act on receiving a new supply of blood from the lungs. These experiments bear immediately upon the point of practice followed in your case, and in that of Dr. Campbell. They show that if, by the simple plan of inversion, combined with artificial respiration, a current of blood could be induced to move over the pulmonic circuit, recovery in many otherwise hopeless cases would be accomplished. This is a fact I have long urged, especially before the London meeting of the Association in I862 ; and I have made many attempts to render the plan practicable, by what I have called artificial circulation. I have introduced a silver tube, attached to a small pump, into the right ventricle, and have tried to pump up blood from the cavx, and force it, by a back stroke, over the lungs. I have also tried to draw the blood over the lung into the arterial channels by aspiration, but I could never succeed in so simplifying either of these methods as to render them practical. The question, therefore, arises: Will the simple method you describe meet the difficulty?

To try to solve this question, I performed yesterday the following experiment. A large strong rabbit was put to sleep with chloroform, and the administration was continued until the animal had ceased to breathe. Tracheotomy was immediately performed : a tube connected with the double acting bellows was inserted into the trachea, and artificial respiration was set up. At the same time, the animal was suspended by its hind legs, with the head downwards. The artificial respiration was steadily carried out, in the most systematic manner, for fifteen minutes, but there was no sign of restoration of the circulation. The animal being still suspended, I next laid open the thorax, and exposed the lungs and heart. The lungs were discovered to be responding perfectly to the action of the double bellows; but all parts of the heart were at rest, except the left auricle : this, charged with red arterial blood, was contracting; the other parts were so dead that they failed to respond to the intermittent galvanic current, although to the same current all the voluntary muscles responded vigorously, and continued to do so for an hour. I observed that the right cavities of the

* Report on the Physiological Action of the Amyl Compounds. - In volume of the Transactions of the British Association, 1865, pp. 272-280). heart, the auricle, and ventricle, were tense with blood. I therefore let the animal down to the horizontal position; and when by this means the pressure of the blood was relieved, the auricle, and afterwards the ventricle, made a few feeble contractions under stimulation. No suffcient force was, however, exerted by the heart to make the blood traverse the pulmonic circuit ; and, I may say, there was not at any time an indication of recovery.

How far the effect of inverting the body was useful in the two cases you have named, it is difficult to say, because in both artificial respiration was employed, and this in itself is so remarkable a means of restoration, that the effects of it have to be seen to be realised. By artificial respiration, I have resuscitated an animal seven minutes after its respiration had been stopped by the inhalation of chloroform; and there are cases in the human subject in which, after complete failure of the respiratory power from chloroform, artificial respiration has restored life, the body being retained in the horizontal position. It would be good practice, nevertheless, after the experience of the cases you have related, to add inversion or partial inversion of the body to the process of artificial respiration. The inversion should not be long sustained; if it be, the heart might be paralysed on its right side from the pressure of the blood, but it should be alternated by return to the horizontal line, the artificial breathing being zealously sustained during the whole time.

In certain cases, where the right heart is demanding the stimulus of blood to enable it to contract with effect, the required supply of blood may thus be obtained from the veins below the heart, and the pulmonic circulation may be restored-a result, if it be instantly resorted to, that will almost of a certainty render artificial respiration successful in restoring life when a volatile narcotic has caused the catastrophe. I remain, dear Cormack, faithfully yours,

B. W. RICHARDSON.

To Sir John Rose Cormack, M.D., F.R.C.P., F.R.S.E.

\section{ON NELATON'S METHOD OF KESUSCITATION FROM CHLOROFORM NARCOSIS.*}

By J. MARION SIMS, M.D., Surgeon to the Woman's Hospital of the State of New York, etc.

Dr. Charles James Campbell, the distinguished accoucheur of Paris, has recently written two papers on anæsthesia in obstetrics, + in which he ably sustains the views long taught by Nélaton, that death from chloroform is due to syncope or cerebral anæmia. And amongst other strong arguments to prove his position, he gave a graphic description of a case of chloroform narcosis, which occurred in my practice in Paris, where M. Nélaton, by his method, unquestionably saved the life of the patient. She was young, beautiful, and accomplished, and belonged to one of the oldest and best families in France. Married at twenty, she gave birth to her first child a year afterwards. The head was enormous (hydrocephalic), impacted in the pelvis nearly 24 hours, and the delivery of a dead child was ultimately accomplished with instruments. Dr. Bouchacour of Lyons was called in consultation, and applied the forceps. In a week afterwards, the urine began to dribble away, and in a fortnight an immense slough was thrown off. The case, surgically considered, was one of the most interesting I ever saw, and the operation was one of the most difficult I ever performed on any one in her station in life. The base of the bladder was destroyed, and the fundus fel] through the fistulous opening; it was therefore inverted, and pro.truded between the labia majora as a herniary mass of the size of an apricot, its external covering being the internal or lining membrane of the bladder, which was of a deep vermillion red colour. The vaginal portion of the cervix uteri and the posterior cul-de-sac were destroyed; and by the reparative process, the cervix and the posterior wall of the vagina were blended into one common cicatricial mass, which was firm, inelastic, and immovable. The case appeared desperate, and $M$. Nélaton had pronounced it incurable. A preparatory operation was necessary, viz., to open the cervix uteri, by dissecting it from the posterior wall of the vagina, and thus to reconstitute the canal of the vagina up to the canal of the cervix ; and by a subsequent operation, to draw forward the flap thus formed, secure it to the neck of the bladder anteriorly, and thereby close the fistula. The first, or preparatory operation, was performed at the country house of the family near Dijon,

* Read before the Surgical Section at the Annual Meeting of the British Medical Association in Norwich, August 1874 .

† x. Mémoire sur l'Anesthésie Obstétricale ; 2. Etude sur la Tolérance Anesthésique Obstétricale, par le Dr. Charles James Campbell, Ancien Interne de la Maternité de Paris, Ancien Chef de Clinique Obstétricale de la Faculté de Paris. G.
Masson. 1874. 